\title{
Problem Behavior and Life Satisfaction in Early Adolescence: Longitudinal Findings in a Chinese Context
}

\author{
Xiaoqin Zhu' ${ }^{1} \cdot$ Daniel T. L. Shek ${ }^{1}$ \\ Accepted: 8 December 2020 / Published online: 9 January 2021 \\ (C) The Author(s) 2021
}

\begin{abstract}
This study tested the reciprocal relationships between problem behavior (PB) and life satisfaction (LS) as well as the relationships between their trajectories of change. Using a threewave dataset collected from 3,328 Chinese junior secondary school students in Hong Kong, this study identified bidirectional associations between PB and LS. For PB, while externalizing behavior was indexed by "delinquent behavior" and "problem behavioral intention", internalizing behavior was indexed by "deliberate self-harm" and "suicidal behavior". As expected, both types of PB negatively predicted future LS. Besides, changes in PB also negatively predicted changes in LS. While the predictions of externalizing behavior on LS were similar among boys and girls and declined over time, the prediction of internalizing behavior appeared to be stronger and more persistent for boys than for girls. A novel finding was that while earlier LS positively predicted later PB, changes in LS negatively predicted changes in PB over time. The present findings underscore the dynamic relationships between problem behavior and life satisfaction over time and across genders in early adolescent years.
\end{abstract}

Keywords Bidirectional relationship · Chinese adolescents $\cdot$ Problem behavior $\cdot$ Life satisfaction · Gender difference

\section{Introduction}

Adolescence has been historically regarded as a difficult period marked by "storm and stress" (Hall 1904). Based on this view, studies have primarily focused on the "dark side" of adolescent development (such as adolescent emotional disorders and problem behavior) without attending to strengths and potentials in adolescents (Steinberg and Lerner 2004). In sharp contrast to this traditional "deficit" view, the positive youth development (PYD) perspective regards adolescents as "resources to develop" and highlights developmental plasticity and diversity as well as strengths and potentials in adolescents (Silbereisen and Lerner 2007; Tolan et al. 2016). Researchers in PYD fields have focused on the "bright

Daniel T. L. Shek

daniel.shek@polyu.edu.hk

1 Department of Applied Social Sciences, The Hong Kong Polytechnic University, Hong Kong, PR China 
side" of adolescents, such as resilience, positive identity, emotional competence, positive functioning, and well-being (Jimerson et al. 2004).

Among multiple positive indicators of youth development, one core indicator is global life satisfaction (LS), which refers to one's cognitive assessment of his or her overall life quality based on his or her own criteria (Diener 2000). According to Park (2004), happiness and personal satisfaction are vital conditions for mental health. Generally speaking, studies have documented that LS is negatively linked with maladaptation during adolescence such as emotional distress and conduct problems and positively associated with favorable outcomes, including high school engagement and good academic achievement (Heffner and Antaramian 2016; Marques et al. 2015; Schei et al. 2016; Bartels et al. 2013).

As measures of adolescent problem behavior (PB), externalizing problems (i.e., negative behavior toward the external world, such as delinquency and aggression) and internalizing problems (i.e., negative psychological processes within the self, such as depression and self-harm) are identified as negative correlates of LS. For example, high school students with lower LS exhibited more violent and aggressive behaviors and they were more likely to use substances than same-aged peers who were more satisfied with life quality (Valois et al. 2001, 2006). Likewise, children and adolescents who were less satisfied with their lives displayed more depressive symptoms and suicidal attempts (Suldo and Huebner 2006; Bray and Gunnell 2006). However, most of the findings are derived from crosssectional data which cannot firmly establish long-term relationships between PB and LS. In particular, it is inconclusive as to whether a higher level of LS predicts a lower level of $\mathrm{PB}$ in future and vice versa. Hence, there is a need to address this knowledge gap through longitudinal research.

\subsection{The Predictive Effect of LS on Adolescent PB}

Theoretically, higher LS has been regarded as a buffer against the development of adolescent PB. Park (2004) argued that positive LS cultivates a general tendency to experience and appraise one's life in positive ways. According to the theory of stress and coping (Lazarus 1991), such a positive thinking style associated with high LS predisposes adolescents to cope with stressful life events and environmental challenges in a positive manner, resulting in more positive emotional and behavioral responses. For example, the negative influence of lacking parents' support on the development of externalizing behavior was weaker for adolescents with high LS than for those with low LS (Suldo and Huebner 2004). In contrast, low LS was found to hinder adolescents from enjoying the benefits of positive life events such as support of teachers (Peng et al., 2020). As such, it can be reasoned that adolescents with high LS are at a lower risk of developing PB when they face adversity.

Besides, adolescents who perceive their lives as highly satisfied are prone to experience more positive emotions. According to Fredrickson's (2001) "broaden-and-build theory", the positive emotional experience associated with high LS can broaden "momentary though-action repertoires and build their enduring personal resources" (p. 219). As interpreted by Park (2004), adolescents experiencing greater positive emotions are more open-minded and they can think and behave with more flexibility and efficiency, expanding intellectual, psychological, and social resources that can help them cope with life stressors in the future. For example, Fredrickson and Joiner (2002) found that positive emotional experience was associated with effective coping. A few longitudinal studies have provided initial support for the above theoretical assertions. For example, LS among adolescents 
negatively predicted externalizing and internalizing problems measured in six months (Lyons et al. 2014; Hanniball et al. 2018), twelve months (Shek 1998), and two years (Haranin et al. 2007). Similarly, Jung and Choi (2017) identified a significant longitudinal negative effect of earlier LS on later adolescent delinquency during early adolescence. Besides, LS has also been identified as a significant mediator on the longitudinal predictive effect of personal attributes or environmental factors on the development of adolescent internalizing and externalizing problems (Suldo and Huebner 2004; Sun and Shek 2012).

To conclude, while high LS and related positive emotions promote adaptive and flexible coping strategies and prepare adolescents for future challenges, lower LS signifies negative emotions and a lack of positive functioning, which would narrow adolescent cognitions and elicit maladaptive coping such as "fight" (e.g., externalizing acts toward the external world) or "flight" (i.e., internalizing behaviors toward the self) (Lyubomirsky et al. 2005).

Despite the substantial support for the positive and protective effects of high LS, some researchers raised a concern about "the dark side of happiness", which hypothesizes that a high level of LS does not necessarily predict favorable outcomes (Gruber et al. 2011; Oishi et al. 2009). "The dark side of LS" is related to the potential cost incurred by a high level of positive emotion that is associated with high LS. For example, Friedman (1993) identified a positive linkage between childhood cheerfulness and prospective mortality risk because positive emotion may increase the likelihood of risk and problem behaviors. Indeed, Yuen and Lee (2003) observed that individuals in a positive emotional state were more inclined to take risks than others in a depressed mood. Other studies also showed that individuals with high levels of positive emotions displayed greater engagement in PB, such as disordered eating, smoking, drinking, and risky sexual behaviors (Cyders and Smith 2008; Martin et al. 2002). According to Gruber et al. (2011), individuals having high LS and positive emotions might be less attentive to risks or overestimate their abilities to resolve the negative consequences associated with risk behaviors.

Another explanation of the "dark side of happiness" is that when one feels satisfied, his or her impetus to change may not be high (Semmer et al. 2005). As remarked by Whillans et al. (2020), feeling worse or dissatisfied with one's current situation may drive an individual to take action to improve the situation (i.e., perform "behavioral remediation" in the long run). In other words, negative feelings, such as those related to low LS, may motivate an individual to rectify his or her behavioral problems, resulting in a positive association between LS and PB. A recent study provided indirect empirical evidence for this thesis by showing a negative prospective prediction of LS on individuals' psychological well-being defined as optimal functioning (Joshanloo 2019).

To sum up, while the "stress and coping theory" and "broaden-and-build theory" imply a negative predictive effect of LS on adolescent PB, the notion of "the dark side of happiness" and related indirective evidence suggest a positive longitudinal relationship between LS and adolescent PB. Thus, there could be two competing theoretical predictions on the role of LS in adolescent PB: (1) LS would negatively predict PB, and (2) LS would positively predict $\mathrm{PB}$.

\subsection{Reciprocal Relationships Between LS and PB}

In addition to the predictive role of LS on PB, PB may also predict LS. Diener and Seligman (2004) commented that an individual's behavioral problem (e.g., externalizing and internalizing disorders) predicts lower perceived well-being such as LS. It can be argued that dysfunctional coping and maladaptive behaviors associated with previous low LS 
would further reduce the likelihood of experiencing positive affect and thus harm adolescent well-being over time (Fredrickson 2001; Lyons et al. 2014). This view echoes the assertation of the self-determination theory that "certain activities and lifestyles, particularly those associated with eudaimonic living, supply the most reliable paths to happiness and positive affect" (DeHaan and Ryan 2014, p. 40). Several studies support the presence of negative predictive effects of PB on LS over time. For example, Lyons et al.'s (2013) study reported that adolescents' externalizing as well as internalizing problems reversely predicted their LS assessed in two years. Similarly, negative emotions intrinsic to internalizing problems such as worries negatively predicted students' LS in one year (Steinmayr et al. 2016). Moreover, maladaptive coping behaviors such as substance abuse in adolescence significantly predicted lower LS in adulthood (Bogart et al. 2007).

While there are conceptual arguments on the bidirectional relationships between LS and PB among adolescents, empirical studies examining the reciprocal relationships are very few and they have yielded equivocal findings. On the one hand, some studies only found a longitudinal predictive effect of LS on PB: Lyons et al. (2014) demonstrated that LS served as a significant negative predictor of externalizing behavior over two years but not vice versa; Jun and Choi (2017) reported a significant one-way effect of LS on adolescent delinquency over time. On the other hand, some studies identified a significant predictive effect of PB on LS. For instance, Yu and Shek (2018) reported that adolescent Internet addiction behavior predicted a decline in LS over time while LS did not predict future Internet addiction behavior. Together with the competing predictions on the role of LS in PB, the current inconclusive picture strongly suggests that there is an urgent need to fill this research gap.

In addition to the expected reciprocal relationships between LS and PB levels among adolescents, it is also important to examine the relationships between trajectories of change in LS and PB. In the field, there are numerous studies outlining the developmental trajectories of some forms of adolescent PB (e.g., delinquency) as well as how LS changes over time during adolescence. For example, research findings showed that there is an inverted U-shape developmental trajectory in adolescent delinquency characterized by an upward trend during early adolescence and a downward trend in late adolescence (Jung and Choi 2017; Shek and Zhu 2018; Le and Stockdale 2011). Besides, LS tends to decrease in adolescence (Proctor et al. 2009; Shek and Liang 2018). However, very few studies have investigated how the trajectories of LS and PB may influence each other (Jung and Choi 2017). One methodological reason is that the existing limited number of longitudinal studies in the field usually collected two waves of data in a relatively short period of time (Haranin et al. 2007; Lyons et al. 2014), which is unable to reveal the relationships between developmental trajectories in LS and PB. Thus, in addition to testing the reciprocal relationships between levels of LS and PB, the present study also attempted to shed light on the relationships between trajectories of change in LS and PB.

\subsection{Gender Differences}

It is noteworthy that adolescent gender may moderate the relationships between LS and PB. Generally speaking, girls demonstrate more internalizing behaviors whereas boys show more externalizing behaviors (Lyons et al. 2014). Past research also suggests gender differences in the associations between PB and LS. For example, the negative linkage between problematic usage of the Internet and LS was significantly stronger among females than that in males (Lachmann et al. 2016). Shek (1998) also reported a stronger longitudinal association between adolescent PB and LS among girls than their male peers. In contrast, 
Lyons et al. (2014) only identified longitudinal predictive effects of LS on internalizing behaviors for boys but not for girls. These conflicting findings suggest that there might be gender differences in how externalizing and internalizing problems are associated with LS. Therefore, this study also attempted to explore the potential moderating effect of adolescent gender.

\subsection{The Present Study}

The present study has two objectives. First, we compared unidirectional and bidirectional relationships between levels of PB and LS among adolescents using a longitudinal design. Our general expectation was that there are bidirectional relationships between PB and LS (Omnibus Hypothesis 1). Based on the literature (e.g., Lyons et al. 2013), we expected negative predictive effects of externalizing behavior and internalizing behavior on LS over a period of time (Hypothesis 1a and Hypothesis 1b, respectively). As the majority of the available empirical evidence suggests negative prediction of LS on PB (Lyons et al. 2014; Jung and Choi 2017), we also expected that adolescent LS would negatively predict their externalizing behavior and internalizing behavior over time (Hypothesis $1 \mathrm{c}$ and $1 \mathrm{~d}$, respectively). Besides, we investigated gender differences in the hypothesized reciprocal relationships between PB and LS among adolescents. Given the mixed research findings in previous studies, we did not propose any specific hypothesis for the potential gender differences.

To test the reciprocal relationships between LS and PB, we used cross-lagged panel analyses to compare four competing models corresponding to four relationship patterns between PB and LS. The four models are summarized in Fig. 1. The first model (Model

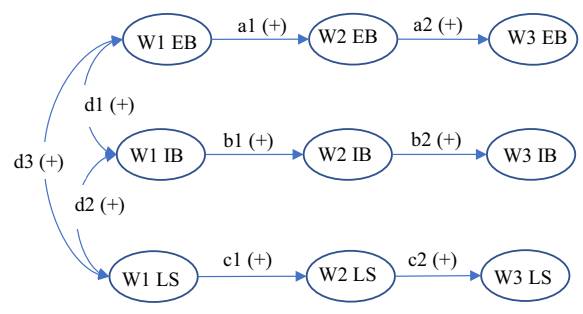

a Model 1: No cross-lagged associations.

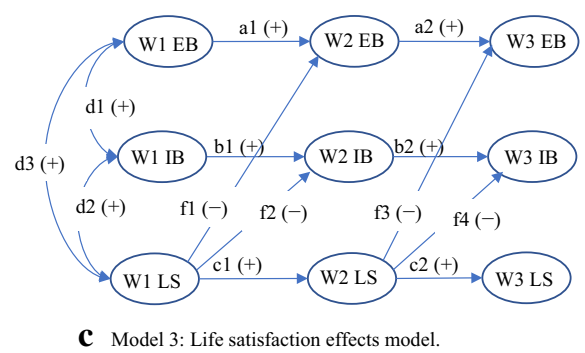

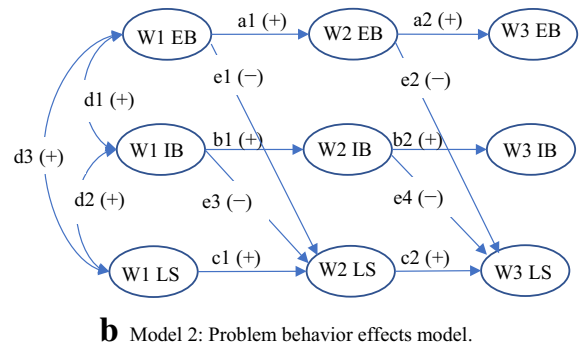

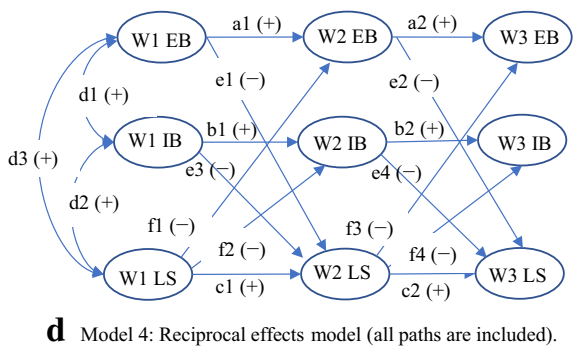

Fig. 1 Autoregressive, cross-lagged panel path models. W1=Wave 1, W2=Wave 2, W3=Wave 3 , $\mathrm{EB}=$ Externalizing behavior, $\mathrm{IB}=$ Internalizing behavior, $\mathrm{LS}=$ Life satisfaction. Externalizing behavior is indexed by delinquent behavior and problem behavioral intention, Internalizing behavior is indexed by deliberate self-harm and suicidal behavior. Variables shown as ovals are latent variables and their indicators (i.e., observed variables) are not shown in the figure 
1, 1a in Fig. 1) is the "no cross-lagged effects" model in which PB and LS do not predict each other directly. The second model (Model 2, 1b in Fig. 1) is the "PB effects" model where direct and negative predictions of externalizing and internalizing behaviors on LS over time are proposed. The third model (Model 3, 1c in Fig. 1) is the "LS effects" model that specifies the direct and negative predictions of LS on two indicators of PB over time. Finally, the last model (Model 4, 1d in Fig. 1) is the "reciprocal effects" model where reciprocal and negative panel relationships between PB and LS are hypothesized. This process of model comparison can effectively detect whether there are reciprocal relationships between PB and LS after statistically controlling autoregressive effects of each construct and contemporaneous correlations between each other. Based on the preceding discussion, we expected that Model 4 would show the best model fit.

Second, we explored whether trajectories of change in PB and LS would predict each other. This research objective was addressed through latent growth modeling, which is a widely adopted technique to capture changes in multiple constructs over time and estimate the associations between the changes (Byrne 2016; Shek and Lin 2017; Jung and Choi 2017). The conceptual diagram of latent growth models is presented in Fig. 2. There are three predictive effects, including 1) $b_{0}$ : the predictive effect of one intercept on the other variable's intercept, 2) $b_{1}$ : the predictive effect of one intercept on the other variable's linear slope, and 3) $b_{2}$ : the predictive effect of one linear slope on the other variable's linear slope (see Fig. 2). While $b_{0}$ represents cross-sectional associations between the initial levels of PB and LS, $b_{1}$ and $b_{2}$ are pertinent to the predictive effects on change rates. Given the expected negative associations between PB and LS, we expected that the initial level (i.e., intercept) of PB (Hypothesis 2a) and its change (i.e., linear slope, Hypothesis 2b) would negatively predict the change in LS (i.e., linear slope) and vice versa (Hypothesis

\section{Problem behaviors $\quad$ Life satisfaction}

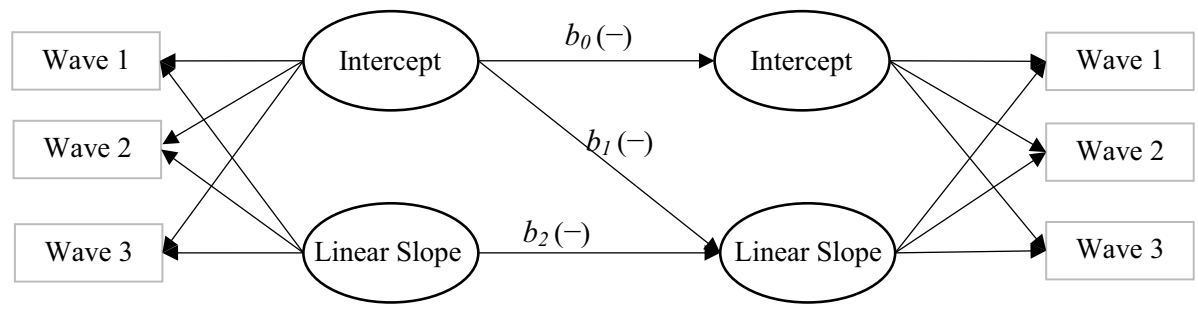

a Problems behaviors predict life satisfaction.

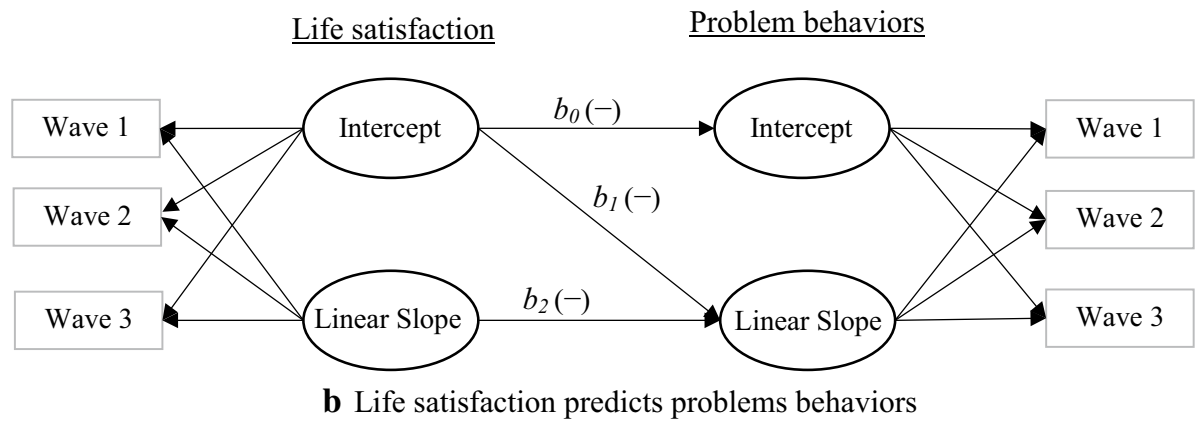

Fig. 2 a Problems behaviors predict life satisfaction. b Life satisfaction predicts problems behaviors 
3a and Hypothesis 3b). Gender differences in the latent growth models were also explored without priori hypotheses because the available findings are not conclusive. Table 1 outlines all the hypotheses to be tested in this study.

In this study, externalizing behavior was indexed by "delinquent behavior" and "problem behavioral intention". For internalizing behavior, it was originally proposed to include depression, anxiety, withdrawal, and other somatic symptoms, which are assessed by measures such as the Child Behavior Checklist (Achenbach 1991). However, as internalizing behavior is interpreted as problem behavior characterized primarily by processes within the self (Liu et al. 2011), deliberate self-harm and suicidal behavior can be regarded as internalizing behavior. For example, Liu et al. (2011) reviewed internalizing disorders and indicated that self-harm and suicidal behavior are internalizing behavior. Besides, self-harm and suicidal behavior were closely related to other types of internalizing problems such as depression (e.g., Hintikka et al. 2009; Nock et al. 2006; Peterson et al. 2008). Furthermore, there are also scales in which items on self-harm and suicide are included to assess internalizing disorders. For example, the widely used Youth Self Report (YSR) has two suicidal/self-harm items in the internalizing behavior scale (Liu et al. 2018; Van Meter et al. 2018). As such, we conceived and assessed internalizing behavior using "deliberate self-harm" and "suicidal behavior" in the present study.

\section{Method}

\subsection{Participants and Procedures}

We used a dataset derived from a large-scale longitudinal project in Hong Kong with the participation of 28 Chinese-speaking secondary schools. This project was launched in the school year of 2009/2010 to investigate Chinese students' adjustment during adolescence. At Wave 1, all students at Grade 7 in these schools were invited to respond to a paper-andpencil survey. In the following years in the secondary school studying period, these students responded to the same survey annually.

This project was approved by the "Human Subjects Ethics Sub-committee" in the institution the authors affiliated to. Before collecting data from students at Wave 1, we obtained fully informed written consent from all related parties including the schools, students, and their parents. At the beginning of each assessment occasion, all participants were clearly explained about the principles of confidentiality, voluntary participation, and free withdrawal.

This study used the data collected in the junior secondary school stage (i.e., Wave 1-3, Grade 7 to Grade 9). A total of 3,328 students completed the survey at Wave 1, among whom 2,905 and 2,860 responded to the same questionnaires at the following two occasions of data collection, respectively. The present study incorporated all the 3,328 participants in the final analyses. The mean age of the working sample $(N=3,328)$ was 12.59 years (standard deviation $=0.74)$ at Wave 1 , and $1,719(51.65 \%)$ among them were boys. 


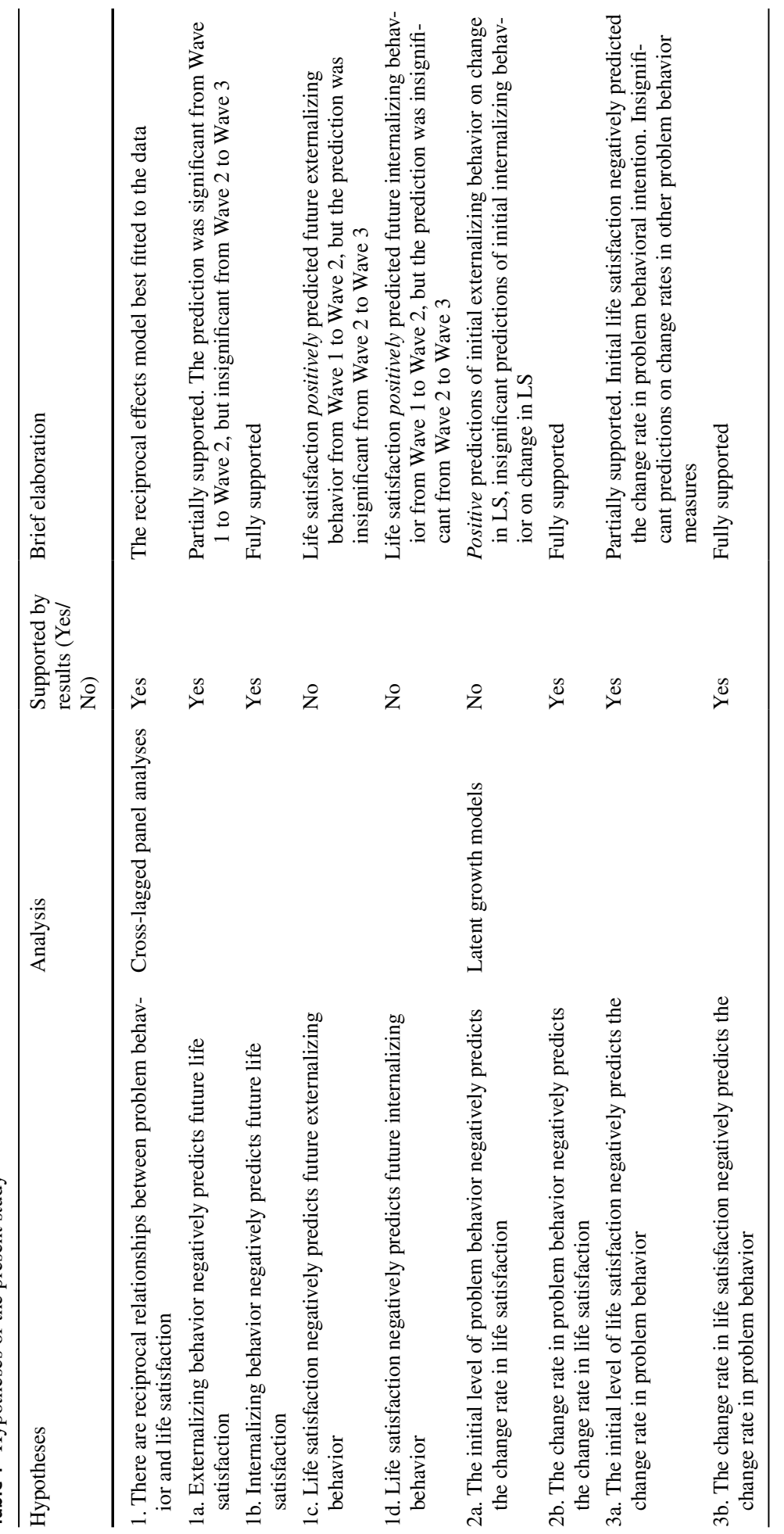




\subsection{Instruments}

Although the survey included multiple measures, the foci of the present study were externalizing behavior (indexed by "delinquent behavior" and "problem behavioral intention"), internalizing behavior (indexed by "deliberate self-harm" and "suicidal behavior"), and LS. These measures are described below.

"Delinquent behavior" was measured by the number of times (" $0=$ never"; " $6=$ more than 10 times") the respondents committed twelve deviant conducts during the past twelve months, including "stealing", "cheating", "truancy", "running away from home", "damaging others' properties", "beating others", "having sexual intercourse with others", "gang fighting", "speaking the foul language", "staying outside the home overnight without parental consent", "bullying" and "trespassing". Some of the behaviors are illegal, such as "stealing" and "damaging others' properties". Some other behaviors, such as "truancy", "running away from home", and "having sexual intercourse with others", are not so serious but considered risky among early adolescents by teachers, parents, and the society in the Chinese communities. The internal consistency of the scale was acceptable in this study as the Cronbach's $\alpha$ s were around 0.80 (see Table 2).

"Problem behavioral intention" was measured as the participants' tendency to engage ("1=absolutely will not"; "4=absolutely will") in five risk behaviors (i.e., "drinking", "smoking", "gambling", "substance consumption", and "having sexual intercourse") in the following two years. This scale demonstrated acceptable reliability as the Cronbach's $\alpha \mathrm{s}$ were around 0.75 (see Table 2).

"Deliberate self-harm" was assessed by participants' engagement ("1=no"; "2="yes") in seventeen self-harm acts (e.g., "wrist cutting", "burning with cigarette or fire" and "self-scratching") in the previous one year. An average score was computed. In this study,

Table 2 Reliability of scales and descriptions of variables across the three waves

\begin{tabular}{|c|c|c|c|c|c|}
\hline Scales/variables & Wave & Cronbach's $\alpha$ & Range & Mean & SD \\
\hline \multicolumn{6}{|l|}{ Externalizing behavior } \\
\hline \multirow[t]{3}{*}{ Delinquent behavior } & Wave 1 & .80 & $0-6$ & .39 & .47 \\
\hline & Wave 2 & .84 & $0-6$ & .46 & .54 \\
\hline & Wave 3 & .80 & $0-6$ & .45 & .50 \\
\hline \multirow[t]{3}{*}{ Problem behavioral intention } & Wave 1 & .74 & $1-4$ & 1.26 & .39 \\
\hline & Wave 2 & .76 & $1-4$ & 1.34 & .45 \\
\hline & Wave 3 & .72 & $1-4$ & 1.37 & .46 \\
\hline \multicolumn{6}{|l|}{ Internalizing behavior } \\
\hline \multirow[t]{3}{*}{ Deliberate self-harm } & Wave 1 & .85 & $1-2$ & 1.04 & .10 \\
\hline & Wave 2 & .87 & $1-2$ & 1.04 & .10 \\
\hline & Wave 3 & .84 & $1-2$ & 1.03 & .08 \\
\hline \multirow[t]{3}{*}{ Suicidal behavior } & Wave 1 & .71 & $1-2$ & 1.08 & .21 \\
\hline & Wave 2 & .72 & $1-2$ & 1.07 & .20 \\
\hline & Wave 3 & .68 & $1-2$ & 1.06 & .19 \\
\hline \multirow[t]{3}{*}{ Life satisfaction } & Wave 1 & .86 & $1-6$ & 3.95 & 1.11 \\
\hline & Wave 2 & .88 & $1-6$ & 3.82 & 1.10 \\
\hline & Wave 3 & .88 & $1-6$ & 3.77 & 1.05 \\
\hline
\end{tabular}


Cronbach's $\alpha$ was $0.85,0.87$, and 0.84 at the three waves, respectively, informing good reliability of the scale (see Table 2).

"Suicidal behavior" was examined by a 3-item scale assessing whether the respondents had suicidal "thoughts", "plans", and "attempts" in the past one year ("1=no"; "2=yes"). An average score was computed to indicate the level of suicidal behavior. Cronbach's $\alpha$ was $0.71,0.72$, and 0.68 at the three waves, respectively, indicating acceptable reliability (see Table 2 ).

"Life satisfaction" was measured by the 5-item Chinese version of "Satisfaction with Life Scale" (SWLS), which has demonstrated good reliability and validity in measuring Chinese people's global LS (Shek et al. 2017; Sun and Shek 2012). We used a 6-point reporting scale (" $1=$ strongly disagree"; " $6=$ strongly agree"). According to Table 2, Cronbach's $\alpha$ s of the SWLS used in this study were above 0.85 at all waves, showing good reliability of the scale.

\subsection{Data Analysis}

Data analyses were conducted through AMOS 25.0 and the "full information maximum likelihood method" was adopted to handle missing data (Arbuckle 2017). First, cross-lagged structural equation modeling (SEM) analyses were conducted to compare the four competing models presented in Fig. 1. In the analyses, externalizing behavior, internalizing behavior, and LS at each wave were latent variables, which were indicated by corresponding observed variables at each wave, respectively. Specifically, externalizing behavior was indexed by "delinquent behavior" and "problem behavioral intention". Internalizing behavior was indexed by "deliberate self-harm" and "suicidal behavior". LS was indicated by the five measuring items.

The following fit indices were used to decide the model fit: the chi-square $\left(\chi^{2}\right)$, "Comparative Fit Index" (CFI), "Non-Normed Fit Index" (NNFI), and "Root Mean Square Error of Approximation" (RMSEA). For both CFI and NNFI, a value greater than 0.90 indicates an acceptable model fit (Kline 2015). Regarding RMSEA, a value below 0.08 is regarded as having an adequate model fit (Kline 2015). In model comparisons, chi-square difference tests were performed to decide the best-fitted model (Schermelleh-Engel et al. 2003). Specifically, a significant decrease in chi-square value along with an increase in the number of freely estimated parameters (i.e., more degrees of freedom) should indicate that the more "complicated" model with more parameters has a better model fit and should be retained (Schermelleh-Engel et al. 2003). Second, after deciding the best-fitted model, multi-group analyses by gender were further performed to test gender differences. Similarly, the chi-square difference tests were utilized to test model fit differences between two sub-samples (boys vs. girls).

Third, to explore the relationships between trajectories of PB and LS, we analyzed several latent growth models as proposed in Fig. 2 to explore the relationships between the change in each adolescent PB measure (i.e., "delinquent behavior", "problem behavior intention", "deliberate self-harm", and "suicidal behavior") and that in LS. As shown in Fig. 2, in each model, latent intercept and linear slope were modeled as a function of the observed variables (i.e., PB indicators or LS items) at the three assessment occasions. As the time interval between every two adjacent assessments was one year, the path from each observed variable to the latent intercept was set as "1" while the paths from observed variables at the three waves to the linear slope were set as " 0 ", 
"1", and "2", respectively. Adolescent gender effects were also tested through multigroup comparisons. CFI, NNFI, and RMSEA were also used to check model fit.

\section{Results}

\subsection{Preliminary Analyses}

Correlational results are shown in Table 3. Externalizing and internalizing behaviors were negatively correlated with LS, both concurrently and longitudinally. It was also found that boys displayed a higher level of externalizing behavior and a lower level of internalizing behavior than did girls across different waves.

\subsection{Unidirectional and Reciprocal Relationships}

As shown in Table 4, the goodness-of-fit measures indicated acceptable model fit of all relationship models (i.e., CFI $>0.90$, NNFI $>0.90$, RMSEA $<0.08$ in all cases) (Kline 2015). First, when the "no cross-lagged effects" model (Model 1) was compared with the "PB effects" model (Model 2), Model 2 better fitted to the data $\left(\Delta \chi^{2}(4)=129.59\right.$, $p<0.001$ ). Second, the "LS effects" model (Model 3) also significantly better fitted to the data than did Model $1\left(\Delta \chi^{2}(2)=16.34, p<0.01\right)$. Third, the "reciprocal effects" model (Model 4) better fitted to the present data than did Model $1\left(\Delta \chi^{2}(8)=144.25, p<0.001\right)$, Model $2\left(\Delta \chi^{2}(4)=14.66, p<0.01\right)$, and Model $3\left(\Delta \chi^{2}(4)=127.91, p<0.001\right)$. As a result, the "reciprocal effects" model best fitted to the present data $\left(\chi^{2}(302)=3225.30, \mathrm{CFI}=0.93\right.$, $\mathrm{NNFI}=0.91$, RMSEA $=0.05)$, supporting the reciprocal relationships between adolescent PB and LS (i.e., Omnibus Hypothesis 1 was supported).

Based on the "reciprocal effects" model, adolescents' PB (externalizing: $\beta=-0.08$, $p<0.01$; internalizing: $\beta=-0.17, p<0.001$ ) at Wave 1 showed significant reverse predictions on LS for the whole sample (see Fig. 3). However, from Wave 2 to Wave 3, while the negative prediction of internalizing behavior on LS remained significant $(\beta=-0.07$, $p<0.05)$, the negative predictive effect of externalizing behavior on LS was insignificant $(\beta=-0.03, p>0.05)$. Overall speaking, the results partially supported Hypothesis 1a and fully supported Hypothesis $1 \mathrm{~b}$. Related findings suggested the negative predictive effects of PB on LS may decline over time during early adolescence.

Adolescents' LS at Wave 1 positively predicted PB at Wave $2(\beta=0.06, p<0.05$ for both PB indicators) for the whole sample (see Fig. 3), which is in contrast to our Hypothesis $1 \mathrm{c}$ and $1 \mathrm{~d}$. However, such effects were not significant from Wave 2 to Wave 3 . Thus, our Hypothesis 1c and 1d were not supported. These findings indicated that higher LS in the first year of junior secondary school study predicted higher levels of adolescent externalizing and internalizing behaviors one year later and such predictive effects diminished when adolescents entered the second year of secondary school study.

\subsection{Gender Differences in the Reciprocal Relationships Between LS and PB}

We further conducted multi-group analyses (boys vs. girls) based on the "reciprocal effects" model (Model 4) to examine whether and how the two sub-samples differ from 


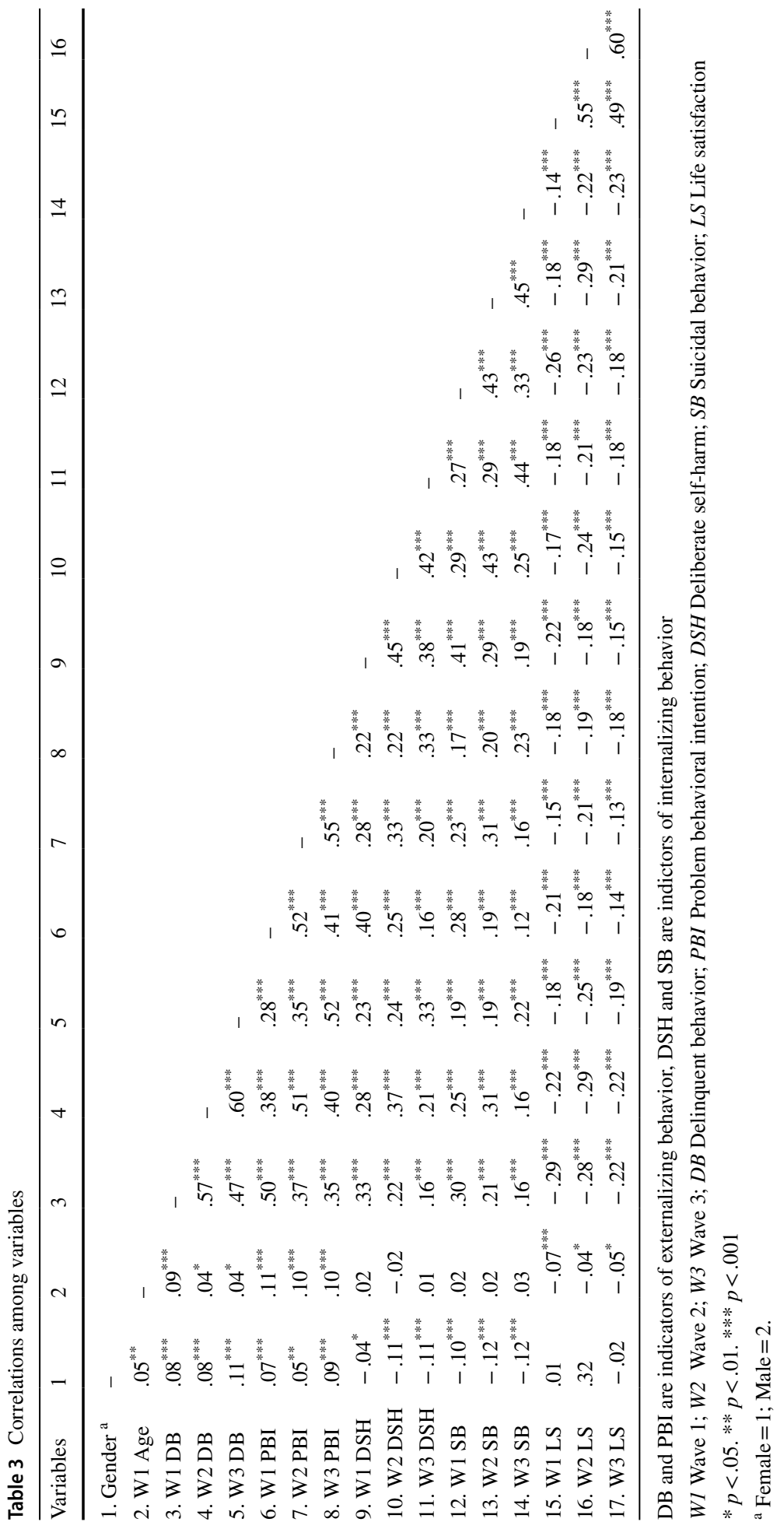




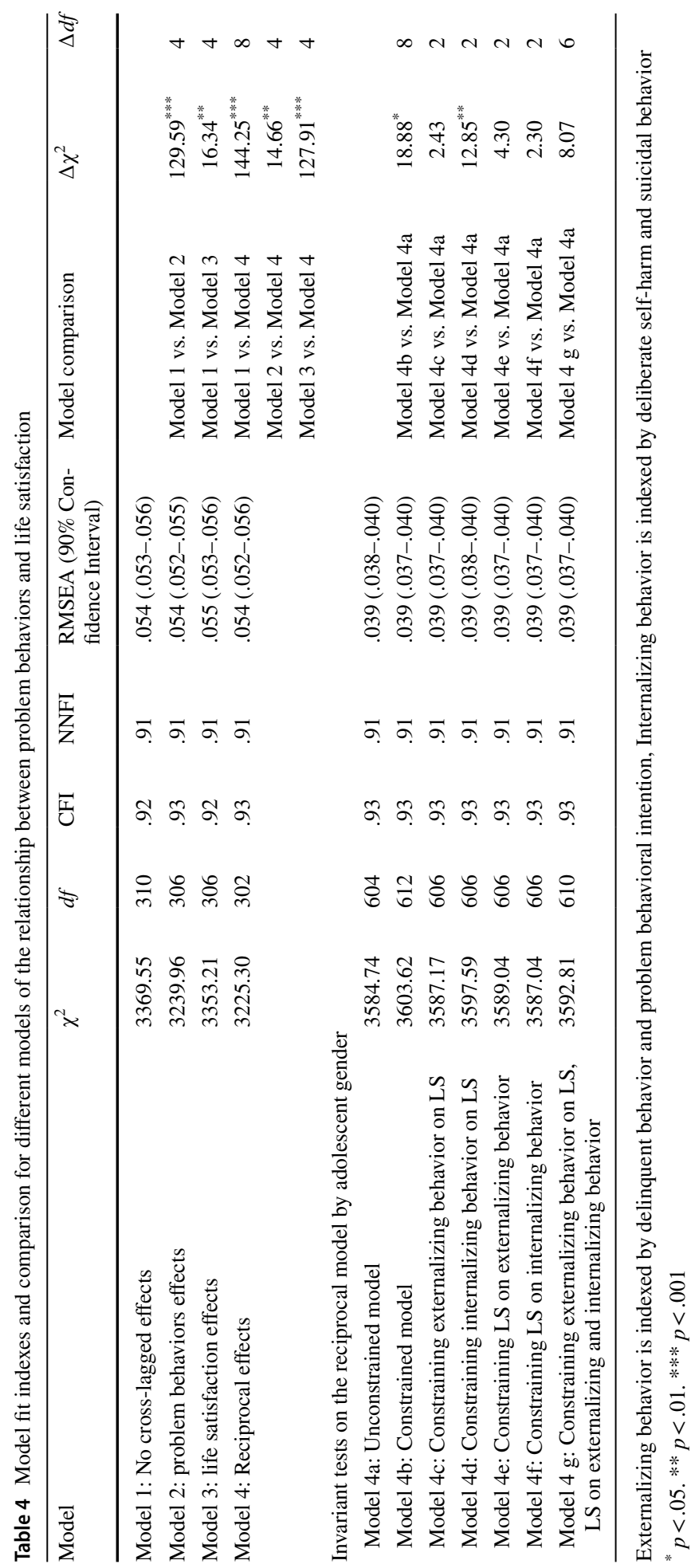




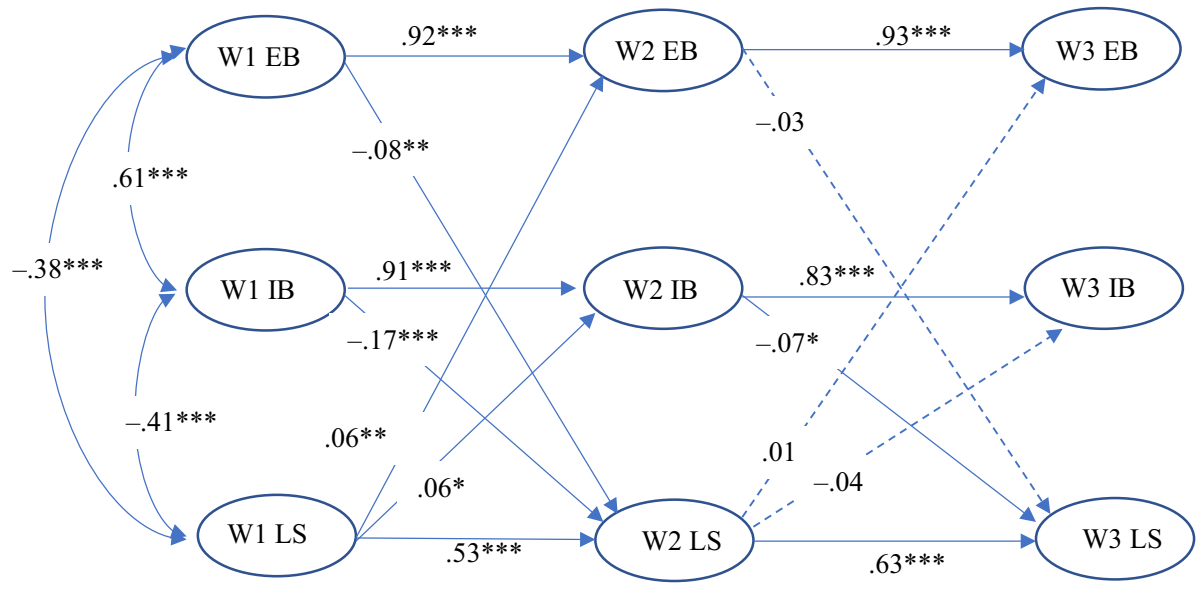

Fig. 3 Standardized path coefficients for the "reciprocal effects" model between problem behavior and life satisfaction based on the whole sample. W1 = Wave $1, \mathrm{~W} 2=$ Wave 2, W3 = Wave 3, EB = Externalizing behavior, IB = Internalizing behavior, LS = Life satisfaction. Externalizing behavior is indexed by delinquent behavior and problem behavioral intention, Internalizing behavior is indexed by deliberate self-harm and suicidal behavior. $\chi_{(302)}^{2}=3225.30, \mathrm{CFI}=.93, \mathrm{NNFI}=.91, \mathrm{RMSEA}=.05$. $* p<.05$, ** $p<.01, * * *$ $p<.001$

each other in the bidirectional relationships between LS and PB. The model comparison results are also shown in Table 4. It was found that both the unconstrained model (i.e., Model 4a, predictive effects between PB and LS were freely estimated across two sub-samples) and the constrained model (i.e., Model 4b, predictive effects between PB and LS were set to be equal across the two sub-samples) fitted to the data adequately (see Table 4). Yet, the two models differed significantly from each other according to the chi-square difference test: $\Delta \chi_{(8)}^{2}=18.88(p<0.05)$.

Subsequent multi-group analyses were performed by constraining one predictive effect (Model 4c: externalizing behavior on LS; Model 4d: internalizing behavior on LS; Model 4e: LS on externalizing behavior; Model 4f: LS on internalizing behavior) to be equal across the two sub-samples. Based on the results depicted in Table 4, the gender difference was significant only in the predictive effect of internalizing behavior on LS $\left(\Delta \chi_{(2)}^{2}=12.85\right.$, $p<0.01)$. As such, this predictive path should be freely estimated while all other paths can be constrained to be equal across gender (i.e., Model $4 \mathrm{~g}$ ).

Based on Model $4 \mathrm{~g}$, regression weights of predictive paths for male and female subsamples are shown in Table 5. Although the negative prospective predictions of internalizing behavior on LS from Wave 1 to Wave 2 were significant for both sub-samples (boys: $\beta=-0.19, p<0.001$; girls: $\beta=-0.13, p<0.001$ ), the prediction seemed to be stronger among boys. In addition, the longitudinal prediction of internalizing behavior on LS from Wave 2 to Wave 3 was significant among boys $(\beta=-0.14, p<0.001)$ but not among girls $(\beta=-0.02, p>0.05)$. The findings suggest a more persistent negative prediction of internalizing on LS among boys. Other predictive effects were equivalent across gender. 
Table 5 Regression weights of paths between problem behaviors and life satisfaction

\begin{tabular}{lllll}
\hline & Dependent variable & $\beta$ & & \\
\cline { 3 - 5 } & & Whole sample & Boys & Girls \\
\hline Externalizing behavior at Wave 1 & Life satisfaction at Wave 2 & $-.08^{* *}$ & $-.09^{* * *}$ & $-.08^{* * *}$ \\
Internalizing behavior at Wave 1 & Life satisfaction at Wave 2 & $-.17^{* * *}$ & $-.19^{* * *}$ & $-13^{* * *}$ \\
Externalizing behavior at Wave 2 & Life satisfaction at Wave 3 & -.03 & -.02 & -.02 \\
Internalizing behavior at Wave 2 & Life satisfaction at Wave 3 & $-.07^{*}$ & $-.14^{* * *}$ & -.02 \\
Life satisfaction at Wave 1 & Externalizing behavior at Wave 2 & $.06^{* *}$ & $.06^{* *}$ & $.07^{* *}$ \\
Life satisfaction at Wave 1 & Internalizing behavior at Wave 2 & $.06^{*}$ & $.06^{*}$ & $.05^{*}$ \\
Life satisfaction at Wave 2 & Externalizing behavior at Wave 3 & .01 & .01 & .01 \\
Life satisfaction at Wave 2 & Internalizing behavior at Wave 3 & -.04 & $-.06^{*}$ & $-.04^{*}$ \\
\hline
\end{tabular}

Externalizing behavior is indexed by delinquent behavior and problem behavioral intention, Internalizing behavior is indexed by deliberate self-harm and suicidal behavior

${ }^{*} p<.05$. ** $p<.01$. *** $p<.001$

\subsection{Relationship Between Developmental Trajectories of LS and PB}

Before testing the relationship between trajectories of change, we first analyzed univariate latent growth curves separately for each measure, including "delinquent behavior", "problem behavioral intention", "deliberate self-harm", "suicidal behavior", and LS. Results yielded adequate model fit and significant means and variances in intercepts and linear slopes for all models. While adolescent delinquent behavior (latent linear slope $=0.04, p<0.001$ ) and problem behavioral intention (latent linear slope $=0.06$, $p<0.001$ ) increased over time, their self-harm (latent linear slope $=-0.003, p<0.01$ ) and suicidal behavior (latent linear slope $=-0.01, p<0.01$ ) slightly declined across waves. There was a linear decrease in adolescent LS (latent linear slope $=-0.09$, $p<0.001)$ as well.

As multi-group (boys vs. girls) comparisons for latent growth models by constraining the three predictive effects (i.e., $b_{0}, b_{1}$, and $b_{2}$ ) did not yield significant gender differences $\left(\Delta \chi^{2}(3)<7.82, p>0.05\right)$, we analyzed latent growth models based on the whole sample. The results are outlined in Table 6 . Models involving predictive effects of adolescent PB on LS or the reverse predictions showed adequate mode fit.

The analyses yielded following findings. First, the initial levels of adolescent PB and LS negatively predicted each other (standardized $b_{0}$ ranged between -0.45 and $-0.31, p s<0.001$ ), supporting the expected bidirectional negative associations between PB and LS. Second, while the initial levels of two externalizing behavior measures ("delinquent behavior" and "problem behavioral intention") positively predicted changes in LS (standardized $b_{1}=0.10, p<0.01$ ), the initial levels of two internalizing behavior indicators ("deliberate self-harm" and "suicidal behavior") did not exert significant predictive effects on the linear slope of LS. These findings suggest that while a lower level of initial externalizing behavior predicted a faster decline in LS, levels of internalizing behavior did not predict the change rate of LS. Findings did not support our Hypothesis $2 a$.

Third, the initial LS level was not a significant predictor of the change rates of delinquent behavior, self-harm, and suicidal behavior. However, it negatively predicted the increase in problem behavioral intention (standardized $b_{1}=-0.07, p<0.05$ ), indicating 


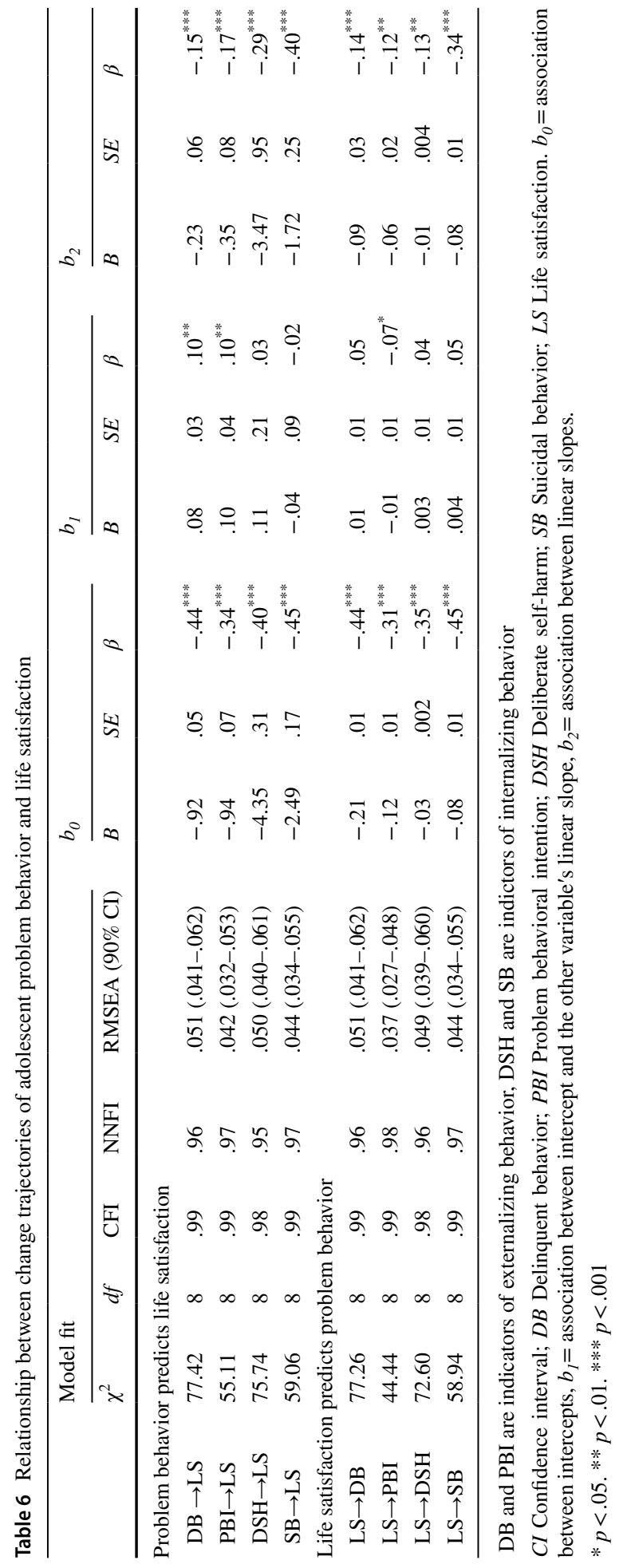


that a higher initial level of LS predicted a slower increase in problem behavioral intention. Thus, the findings partially supported Hypothesis $3 \mathrm{a}$.

Fourth, the linear slopes of PB and LS negatively predicted each other (standardized $b_{2}$ ranged between -0.40 and $-0.12, p \mathrm{~s}<0.05$ ). The findings suggest that a faster increase in externalizing behavior or a slower decrease in internalizing behavior predicted a faster drop in LS, supporting Hypothesis 2b. Likewise, a faster decline in LS predicted a faster increase in externalizing behavior and a slower decrease in internalizing behavior, supporting Hypothesis $3 \mathrm{~b}$.

To give a clear picture of the hypotheses and the results of the analyses, the findings of the present study are summarized in Table 1 with reference to hypotheses.

\section{Discussion}

\subsection{Reciprocal Relationships Between LS and PB}

Omnibus Hypothesis 1 was supported. The present findings based on cross-lagged models support reciprocal relationships between PB and LS among early adolescents. The reciprocal relationships were further triangulated by the findings of the latent growth models: the intercepts $\left(b_{0}\right)$ of PB and LS were negatively associated with each other and the latent linear slopes $\left(b_{2}\right)$ of PB and LS also negatively predicted each other (see Table 6). This observation is inconsistent with those studies which only identified a one-way predictive effect of LS on PB rather than reciprocal associations (Lyons et al. 2014; Jung and Choi 2017). Nevertheless, while the bidirectional associations were significant during the first two waves in our study, most of the associations declined and become insignificant after Wave 2. Thus, the relationship between LS and PB may change over time. In line with this conjecture, a recent study in the United States identified reciprocal effects between adolescent LS and their coping behaviors including externalizing and internalizing behaviors while the directionality of the effect varied across waves (Jiang et al. 2019). As a result, the mixed findings in previous studies may be due to the fact that there were only two assessment occasions, which were unable to reveal such changes (Lyons et al. 2014; Barendregt et al. 2018).

The inconsistent findings may be also attributable to different methodologies used in studies. In the present study, cross-lagged analyses also indicated greater temporal stability in PB than in LS as indicated by the stronger autoregressive effects across time for the two PB measures than for LS (see Fig. 3). Compared with adolescent PB which determines its future value to a large extent (Raaijmakers et al. 2005; Shek and Zhu 2019), LS can vary more due to the influence of emotional, behavioral, and contextual factors (Sheldon and Lucas 2014). Thus, in the present cross-lagged models, when autoregressive paths were controlled, PB was more likely to exert a prospective prediction on LS. However, previous studies using hierarchical regression analyses based on two waves of data were not able to rule out the influence of the autoregressive effects of both constructs (Lyons et al. 2014). Indirect support for this conjecture can be found in Joshanloo's (2019) study, which also adopted cross-lagged analyses and found that a longitudinal stable construct (i.e., psychological well-being) tended to have a stable predictive effect on LS. Nevertheless, more longitudinal studies are needed to replicate and verify the present findings. 


\subsection{The Predictive Effects of PB on LS}

Our hypotheses about the negative predictive effect of adolescent PB on LS were largely supported: Hypothesis 1a and 1b supported by the cross-lagged model are consistent with Hypothesis $2 \mathrm{~b}$ supported by latent growth models (see Table 1 ). More specifically, the present study found that higher levels of PB at Wave 1 predicted lower levels of LS at Wave 2 in the cross-lagged model, which is consistent with previous findings (Bukhari and Saba 2017; Schei et al. 2016; Lyons et al. 2013; Bogart et al. 2007; van Den Eijnden et al. 2018). This result also echoes the negative predictive effects of PB intercept on the intercept of LS (i.e., $\left.b_{0}<0\right)$ in latent growth models.

These findings support Evans's (1994) "biosocial-cognitive" model, where PB is a type of social behavior that acts as a proximal antecedent of LS while personality and environmental factors are remote predictors of LS (Fogle et al. 2002; Lyons et al. 2013). Besides, it was found that children's PB would lead to negative familial factors such as higher parental psychological control, more family conflicts, less parental warmth, and poorer parent-child relationships, all of which contribute to a decrease in adolescent LS (Zhu and Shek 2020). Together with previous findings, our results suggest that engagement in PB represents negative life experience which would eventually predict deterioration in adolescents' overall quality of life. Our study also extended the previous findings by showing the negative predictive effects of changes in PB on the change slope in LS (see Table 1, Hypothesis 2b). Specifically, a faster increase in externalizing problems or a slower decrease in internalizing problems predicted a faster decrease in LS (i.e., $b_{2}<0$ ). An increase in self-harm and suicidal behavior would create sad moods such as loneliness and make the adolescent less satisfied with life (Rönkä et al. 2013; Valois et al. 2004).

However, Hypothesis 1a was only partially supported because the prediction of externalizing behavior was no longer significant from Wave 2 to Wave 3 . The diminished predictive effect can be accounted for by the finding in the latent growth model that the initial externalizing behaviors positively predicted the change in LS, which is inconsistent with our Hypothesis 2a (see Table 1). As higher levels of externalizing problems were associated with a slower decrease in LS, the discrepancy in LS between adolescents with higher or lower levels of externalizing behavior became smaller gradually, causing the gradual diminishing in the predictive effect of the externalizing problems. Although the congruent results obtained from different analyses provide "triangulation", the positive associations between latent intercepts of PB and linear change slope of LS are unexpected. It might be due to a floor effect-as LS of those adolescents having higher PB was relatively low at Wave 1, the room for such a low LS to drop quickly over time was not big. Thus, the association between initial PB and change in LS was insignificant or even positive. This floor effect may also explain the insignificant associations between intercept and linear slope among PB and other psychological factors reported in previous studies (Shek and Lin 2017; Jung and Choi 2017). Nevertheless, the present positive associations are novel and need to be interpreted with caution and verified in future studies.

Although Hypothesis 1b was fully supported, the effect of internalizing behavior declined yet remained significant from Wave 2 to Wave 3 . This finding echoes the insignificant predictive effect of initial internalizing behavior on the change slope of LS (see Table 1, Hypothesis 2a). The findings also suggest that internalizing behavior may have a more persistent negative predictive effect on LS than externalizing behavior. Such an interpretation is in line with Jiang et al.'s (2019) observation that internalizing coping, but not externalizing coping, showed a significant negative longitudinal prediction on LS. 
However, it is in contrast to Lyons et al.'s (2013) finding that self-reported externalizing behavior exerted a more stable prediction on LS than did internalizing behavior. In view of the inconclusive picture, more longitudinal studies covering a longer period of time are warranted to decide the relative magnitude of the predictive effects exerted by externalizing and internalizing problems.

In addition, the negative predictive effect of internalizing behavior on LS appeared to be stronger and more robust for boys than for girls. This is inconsistent with the previous findings showing a stronger negative association between earlier PB and later LS for girls (Shek 1998). Some scholars argued that girls may be more vulnerable to negative influences of internalizing behavior because they generally display higher levels of internalizing behavior than do boys (Lyons et al. 2014; Bartels et al. 2013). However, the present finding does not support this notion. A possible explanation may be related to different emotional expression norms between girls and boys (Cassano and Zeman 2010). For example, parents were found to be more sensitive and responsive to daughters' sadness and sons' angry emotions (Fivush et al. 2000; Cassano et al. 2007). As internalizing problems are more related to sadness but not angry emotions, parents are likely to respond to daughters' internalizing problems in a supportive way while being irresponsive or even non-supportive to sons' internalizing problems. Therefore, adolescent boys might suffer a more significant decrease in LS as compared to girls as a result of different parental responses. Although this conjecture makes sense, it is yet to be verified in future empirical studies.

\subsection{The Predictive Effects of LS on PB}

Regarding the predictive effect of LS on PB as the second aspect of the reciprocal relationship, findings are discordant with Hypothesis 1c and 1d (see Table 1): LS was in fact a positive longitudinal predictor of both externalizing and internalizing behaviors from Wave 1 to Wave 2. This finding is inconsistent with the known protective effect of positive LS against PB identified in previous research (Haranin et al. 2007; Lyons et al. 2014; Jung and Choi 2017; Moksnes et al. 2016). However, the present finding can be understood in the light of "the dark side of happiness", which indicates that great LS may also predict unfavorable outcomes (Gruber et al. 2011; Oishi et al. 2009).

Theoretically, emotional conditions associated with high LS may influence adolescents' cognitive and social functioning, such as how they collect and process information and interact with others. On the one hand, adolescents with high LS may be inattentive to environmental risks and tend to underestimate the negative consequences of PB (Gruber et al. 2011). Indeed, individuals with high positive emotional states were found to overlook essential threats and have a higher level of risk tolerance (Baumeister et al. 2001; Grable and Roszkowski 2008). People displayed more risky behaviors (e.g., risky sexual behaviors and substance consumption) when they have higher levels of positive emotion (Cyders and Smith 2008; Zapolski et al. 2009). On the other hand, the absence of certain negative emotions may increase the likelihood of developing PB (Oishi et al. 2009). For example, scholars noted that adolescents having high LS could be less likely to experience guilt and shame if they engage in delinquency, which may subsequently lead to moral transgressions and even more delinquent behaviors (Jung and Choi 2017; Baumeister et al. 1994).

Furthermore, when individuals feel satisfied, they might not have much motivation to change while dissatisfied individuals may be internally motivated to improve and display healthier behavior (Oishi et al. 2009; Heinberg et al. 2001). As such, adolescents with high LS may be less motivated to take initiative to change their behavioral problems. This might 
be particularly plausible if taking into consideration the unique interpretation of "hedonic" well-being in Chinese culture. While there are proposals emphasizing the importance of "hedonic" well-being in terms of enjoyment, pleasant experience, and satisfaction (Huta and Ryan 2010), traditional Chinese culture does not endorse the pursuit of hedonistic goals such as emotional pleasure (Zhang and Veenhoven 2008; Yang and Zhou 2017). Instead, "no pain, no gain" in terms of overcoming adversity, self-cultivation, and contribution to society are strongly favored (Lu 2001). As such, a lack of "hedonic" well-being indicated by LS among Chinese adolescents may not necessarily reflect "unpleasant experience". Instead, low LS may indicate Chinese adolescents' devotion to other fundamental aspects of obtaining happiness such as meaning and contribution, which would be associated with low levels of PB.

Despite the above-mentioned mechanisms, the positive predictive effect of LS on PB indicators became insignificant from Wave 2 to Wave 3 (see Table 1, Hypothesis 1c and Hypothesis 1d). In fact, the protective effects of LS were identified in the latent growth models (see Table 1, Hypothesis 3a and Hypothesis 3b). Specifically, higher initial LS was associated with a slower increase in problem behavior intention. Besides, a slower decrease in LS was linked with a faster decline in internalizing behavior and a slower increase in externalizing behavior. These seemingly inconsistent predictions of LS suggest a change in the prospective prediction of LS on PB over time, which echoes Joshanloo's (2019) conclusion that there may be positive, negative, or nonsignificant predictions of LS on psychological well-being across various time points. It appears that the existing findings support claims on both "protective effect of LS" and "the dark side of LS", suggesting the relationship between LS and future developmental outcomes may be nonlinear and vary across situations. For example, high LS may act as a short-term protective factor while low LS might motivate an individual to strive for positive changes in the long-run (Whillans et al. 2020; Joshanloo 2019). In addition, high LS appears to be more likely to have a negative influence on adolescents already having behavioral problems (Jung and Choi 2017; Baumeister et al. 2003). Future studies will certainly benefit from replicating the present findings and investigating possible mechanisms underlying the change in the predictive effect of LS on PB.

\subsection{Implications}

Theoretically speaking, there are several observations of the present findings based on the cross-legged and latent growth models. First, while there is support for the common conjecture that LS is negatively associated with adolescent PB (e.g., findings in latent growth models), LS was also found to positively predict PB. Second, there is support for the alternative view that PB negatively predicts LS. Third, the relationships between LS and PB are bidirectional in nature. Fourth, there is some gender difference in the prediction of internalizing behavior on LS. Fifth, the initial level of LS was negatively related to the change in problem behavior intention. Sixth, linear change slopes in LS and PB negatively predicted each other. Some of these observations are novel in this field and form the basis for future studies.

The present findings also have important practical implications. First, the negative predictive effects of PB on future LS found in both cross-lagged analyses and latent growth models inform early efforts to prevent or mitigate behavioral problems as well as to promote LS among adolescents. For example, universal PYD programs should be meticulously designed and implemented to enhance adolescents' psychosocial competence, which 
will enable them to resist the risks of developing PB (Shek and Wu 2016). Moreover, when students enter secondary schools, systematic psychological screening tools should be utilized to accurately identify at-risk youth so that tailor-made interventions can be employed to help them minimize negative outcomes. Second, although promoting LS has been generally considered a source of positive outcomes and the present latent growth models also revealed a protective effect of LS, yet it positively predicted future PB in cross-lagged analyses. Thus, high LS and its associated positive emotional states may bring negative outcomes at a certain circumstance. Youth workers should be aware of and understand this possibility. Furthermore, efforts should be devoted to helping early adolescents develop and use adaptive strategies to regulate both positive and negative emotions (Gilbert 2012). This is of paramount importance because early adolescents are especially vulnerable to emotional dysregulation due to pubertal changes and not yet fully developed emotional and cognitive capacities (Zeman et al. 2006; Dahl 2004).

\subsection{Limitations}

This study expands our knowledge and understanding of the relationships between LS and PB among early adolescents and over time. Nevertheless, several limitations should be noted. First, assessment of LS and PB solely relied on self-report questionnaires, which may result in concerns of the method variance. Thus, it will be better to involve multiple reporters, such as parents and teachers, in future studies. Besides, both externalizing and internalizing problems were assessed by two indicators only. Future studies should include more forms of behavioral problems such as aggression and depression. Second, the present study covered three years in early adolescence. It will be inspiring to cover a longer time span (e.g., childhood and late adolescence) to detect how the bidirectional relationships between LS and PB vary and develop over time. Third, based on the regression coefficients, the reciprocal relationships only showed small effect sizes. Thus, it is important to interpret the current results with caution and replication studies are warranted.

Acknowledgements This research and the 6-wave longitudinal study in the Project P.A.T.H.S. are financially supported by The Hong Kong Jockey Club Charities Trust (Project Code: 5-ZH67).

\section{Compliance with Ethical Standards}

Conflict of interest The authors declare that they have no conflict of interest.

Informed Consent This project was approved by the "Human Subjects Ethics Sub-committee" in the institution the authors affiliated to. Before collecting data from students at Wave 1, we obtained fully informed written consent from all related parties including the schools, students, and their parents. At the beginning of each assessment occasion, all participants were clearly explained about the principles of confidentiality, voluntary participation, and free withdrawal.

Open Access This article is licensed under a Creative Commons Attribution 4.0 International License, which permits use, sharing, adaptation, distribution and reproduction in any medium or format, as long as you give appropriate credit to the original author(s) and the source, provide a link to the Creative Commons licence, and indicate if changes were made. The images or other third party material in this article are included in the article's Creative Commons licence, unless indicated otherwise in a credit line to the material. If material is not included in the article's Creative Commons licence and your intended use is not permitted by statutory regulation or exceeds the permitted use, you will need to obtain permission directly from the copyright holder. To view a copy of this licence, visit http://creativecommons.org/licenses/by/4.0/. 


\section{References}

Achenbach, T. M. (1991). Manual for the child behaviour checklist/4-18 and profile. Burlington, VT: University of Vermont, Department of Psychiatry.

Arbuckle, J. L. (2017). IBM SPSS Amos 25 user's guide. Crawfordville, FL: Amos Development Corporation.

Barendregt, C. S., Van der Laan, A. M., Bongers, I. L., \& Van Nieuwenhuizen, C. (2018). Quality of life, delinquency and psychosocial functioning of adolescents in secure residential care: testing two assumptions of the Good Lives Model. Child and Adolescent Psychiatry and Mental Health. https:// doi.org/10.1186/s13034-017-0209-9.

Bartels, M., Cacioppo, J. T., van Beijsterveldt, T. C., \& Boomsma, D. I. (2013). Exploring the association between well-being and psychopathology in adolescents. Behavior Genetics, 43(3), 177-190. https:// doi.org/10.1007/s10519-013-9589-7.

Baumeister, R. F., Bratslavsky, E., Finkenauer, C., \& Vohs, K. D. (2001). Bad is stronger than good. Review of General Psychology, 5(4), 323-370. https://doi.org/10.1037/1089-2680.5.4.323.

Baumeister, R. F., Campbell, J. D., Krueger, J. I., \& Vohs, K. D. (2003). Does high self-esteem cause better performance, interpersonal success, happiness, or healthier lifestyles? Psychological Science in the Public Interest, 4(1), 1-44. https://doi.org/10.1111/1529-1006.01431.

Baumeister, R. F., Stillwell, A. M., \& Heatherton, T. F. (1994). Guilt: an interpersonal approach. Psychological Bulletin, 115(2), 243-267. https://doi.org/10.1037/0033-2909.115.2.243.

Bogart, L. M., Collins, R. L., Ellickson, P. L., \& Klein, D. J. (2007). Are adolescent substance users less satisfied with life as young adults and if so, why? Social Indicators Research, 81(1), 149-169. https:// doi.org/10.1007/s11205-006-0019-6.

Bray, I., \& Gunnell, D. (2006). Suicide rates, life satisfaction and happiness as markers for population mental health. Social Psychiatry and Psychiatric Epidemiology, 41(5), 333-337. https://doi.org/10.1007/ s00127-006-0049-z.

Bukhari, S. R., \& Saba, F. (2017). Depression, anxiety and stress as negative predictors of life satisfaction in university students. Rawal Medical Journal, 42(2), 255-257.

Byrne, B. M. (2016). Structural equation modeling with AMOS: Basic concepts, applications, and programming (3rd ed.). New York: Routledge.

Cassano, M. C., Perry-Parrish, C., \& Zeman, J. (2007). Influence of gender on parental socialization of children's sadness regulation. Social Development, 16(2), 210-231. https://doi.org/10.111 1/j.1467-9507.2007.00381.x.

Cassano, M. C., \& Zeman, J. L. (2010). Parental socialization of sadness regulation in middle childhood: The role of expectations and gender. Developmental Psychology, 46(5), 1214-1226. https://doi. org/10.1037/a0019851.

Cyders, M. A., \& Smith, G. T. (2008). Emotion-based dispositions to rash action: positive and negative urgency. Psychological Bulletin, 134(6), 807-828. https://doi.org/10.1037/a0013341.

Dahl, R. E. (2004). Adolescent brain development: a period of vulnerabilities and opportunities. Keynote address. Annals of the New York Academy of Sciences, 1021(1), 1-22, doi:https://doi.org/10.1196/ annals.1308.001.

DeHaan, C. R., \& Ryan, R. M. (2014). Symptoms of wellness: Happiness and eudaimonia from a selfdetermination perspective. In K. M. Sheldon \& R. E. Lucus (Eds.), Stability of happiness: Theories and evidence on whether happiness can change (pp. 37-55). Amsterdam, the Netherlands: Elsevier.

Diener, E. (2000). Subjective well-being: The science of happiness and a proposal for a national index. American Psychologist, 55(1), 34-43. https://doi.org/10.1037/0003-066X.55.1.34.

Diener, E., \& Seligman, M. E. P. (2004). Beyond money: Toward an economy of well-being. Psychological Science in the Public Interest, 5(1), 1-31. https://doi.org/10.1111/j.0963-7214.2004.00501001.x.

Evans, D. R. (1994). Enhancing quality of life in the population at large. Social Indicators Research, 33(13), 47-88. https://doi.org/10.1007/BF01078958.

Fivush, R., Brotman, M. A., Buckner, J. P., \& Goodman, S. H. (2000). Gender differences in parent-child emotion narratives. Sex Roles, 42(3-4), 233-253. https://doi.org/10.1023/A:1007091207068.

Fogle, L. M., Huebner, E. S., \& Laughlin, J. E. (2002). The relationship between temperament and life satisfaction in early adolescence: Cognitive and behavioral mediation models. Journal of Happiness Studies, 3(4), 373-392. https://doi.org/10.1023/A:1021883830847.

Fredrickson, B. L. (2001). The role of positive emotions in positive psychology: The broadenand-build theory of positive emotions. American Psychologist, 56(3), 218-226. https://doi. org/10.1037/0003-066X.56.3.218.

Fredrickson, B. L., \& Joiner, T. (2002). Positive emotions trigger upward spirals toward emotional wellbeing. Psychological Science, 13(2), 172-175. https://doi.org/10.1111/1467-9280.00431. 
Friedman, H. S., Tucker, J. S., Tomlinson-Keasey, C., Schwartz, J. E., Wingard, D. L., \& Criqui, M. H. (1993). Does childhood personality predict longevity? Journal of Personality and Social Psychology, 65(1), 176-185. https://doi.org/10.1037/0022-3514.65.1.176.

Gilbert, K. E. (2012). The neglected role of positive emotion in adolescent psychopathology. Clinical Psychology Review, 32(6), 467-481. https://doi.org/10.1016/j.cpr.2012.05.005.

Grable, J. E., \& Roszkowski, M. J. (2008). The influence of mood on the willingness to take financial risks. Journal of Risk Research, 11(7), 905-923. https://doi.org/10.1080/13669870802090390.

Gruber, J., Mauss, I. B., \& Tamir, M. (2011). A dark side of happiness? How, when, and why happiness is not always good. Perspectives on Psychological Science, 6(3), 222-233. https://doi.org/10.1177/17456 91611406927.

Hall, G. S. (1904). Adolescence: Its psychology and its relations to physiology, anthropology, sociology, sex, crime, religion and education. New York, NY: D. Appleton \& Company.

Hanniball, K. B., Viljoen, J. L., Shaffer, C. S., Bhatt, G., Tweed, R., Aknin, L. B., et al. (2018). The role of life satisfaction in predicting youth violence and offending: a prospective examination. Journal of interpersonal violence. https://doi.org/10.1177/0886260518805103.

Haranin, E. C., Huebner, E. S., \& Suldo, S. M. (2007). Predictive and incremental validity of global and domain-based adolescent life satisfaction reports. Journal of Psychoeducational Assessment, 25(2), 127-138. https://doi.org/10.1177/0734282906295620.

Heffner, A. L., \& Antaramian, S. P. (2016). The role of life satisfaction in predicting student engagement and achievement. Journal of Happiness Studies, 17(4), 1681-1701. https://doi.org/10.1007/s1090 2-015-9665-1.

Heinberg, L. J., Thompson, J. K., \& Matzon, J. L. (2001). Body image dissatisfaction as a motivator for healthy lifestyle change: Is some distress beneficial? In R. H. Striegel-Moore \& L. Smolak (Eds.), Eating disorders innovative directions in research and practice (pp. 215-232). Washington, DC: American Psychological Association.

Hintikka, J., Tolmunen, T., Rissanen, M.-L., Honkalampi, K., Kylmä, J., \& Laukkanen, E. (2009). Mental disorders in self-cutting adolescents. Journal of Adolescent Health, 44(5), 464-467. https://doi. org/10.1016/j.jadohealth.2008.10.003.

Huta, V., \& Ryan, R. M. (2010). Pursuing pleasure or virtue: The differential and overlapping well-being benefits of hedonic and eudaimonic motives. Journal of Happiness Studies, 11(6), 735-762. https:// doi.org/10.1007/s10902-009-9171-4.

Jiang, X., Fang, L., \& Lyons, M. D. (2019). Is life satisfaction an antecedent to cping behaviors for adolescents? Journal of Youth and Adolescence, 48(11), 2292-2306. https://doi.org/10.1007/s10964-01901136-6.

Jimerson, S. R., Sharkey, J. D., Nyborg, V., \& Furlong, M. J. (2004). Strength-based assessment and school psychology: A summary and synthesis. The California School Psychologist, 9(1), 9-19. https://doi. org/10.1007/bf03340903.

Joshanloo, M. (2019). Investigating the relationships between subjective well-being and psychological wellbeing over two decades. Emotion, 19(1), 183-187. https://doi.org/10.1037/emo0000414.

Jung, S., \& Choi, E. (2017). Life satisfaction and delinquent behaviors among Korean adolescents. Personality and Individual Differences, 104, 104-110. https://doi.org/10.1016/j.paid.2016.07.039.

Kline, R. B. (2015). Principles and practice of structural equation modeling (4th ed.). New York: The Guilford Press.

Lachmann, B., Sariyska, R., Kannen, C., Cooper, A., \& Montag, C. (2016). Life satisfaction and problematic Internet use: Evidence for gender specific effects. Psychiatry Research, 238, 363-367. https://doi. org/10.1016/j.psychres.2016.02.017.

Lazarus, R. S. (1991). Emotion and adaptation. New York: Oxford University Press.

Le, T. N., \& Stockdale, G. (2011). The influence of school demographic factors and perceived student discrimination on delinquency trajectory in adolescence. Journal of Adolescent Health, 49(4), 407-413. https://doi.org/10.1016/j.jadohealth.2011.02.003.

Liu, J., Chen, X., \& Lewis, G. (2011). Childhood internalizing behaviour: analysis and implications. Journal of Psychiatric Mental Health Nursing, 18(10), 884-894. https://doi.org/10.111 1/j.1365-2850.2011.01743.x.

Liu, Z.-Z., Chen, H., Bo, Q.-G., Chen, R.-H., Li, F.-W., Lv, L., et al. (2018). Psychological and behavioral characteristics of suicide attempts and non-suicidal self-injury in Chinese adolescents. Journal of Affective Disorders, 226, 287-293. https://doi.org/10.1016/j.jad.2017.10.010.

Lu, L. (2001). Understanding happiness: A look into the Chinese folk psychology. Journal of Happiness Studies, 2(4), 407-432. https://doi.org/10.1023/A:1013944228205. 
Lyons, M. D., Huebner, E. S., Hills, K. J., \& Van Horn, M. L. (2013). Mechanisms of change in adolescent life satisfaction: A longitudinal analysis. Journal of School Psychology, 51(5), 587-598. https://doi. $\operatorname{org} / 10.1016 /$ j.jsp.2013.07.001.

Lyons, M. D., Otis, K. L., Huebner, E. S., \& Hills, K. J. (2014). Life satisfaction and maladaptive behaviors in early adolescents. School Psychology Quarterly, 29(4), 553-566. https://doi.org/10.1037/spq00 00061.

Lyubomirsky, S., King, L., \& Diener, E. (2005). The benefits of frequent positive affect: Does happiness lead to success? Psychological Bulletin, 131(6), 803-855. https://doi.org/10.1037/0033-2909.131.6.803.

Marques, S. C., Lopez, S. J., Fontaine, A. M., Coimbra, S., \& Mitchell, J. (2015). How much hope is enough? Levels of hope and students' psychological and school functioning. Psychology in the Schools, 52(4), 325-334. https://doi.org/10.1002/pits.21833.

Martin, L. R., Friedman, H. S., Tucker, J. S., Tomlinson-Keasey, C., Criqui, M. H., \& Schwartz, J. E. (2002). A life course perspective on childhood cheerfulness and its relation to mortality risk. Personality and Social Psychology Bulletin, 28(9), 1155-1165. https://doi.org/10.1177/01461672022812001.

Moksnes, U. K., Løhre, A., Lillefjell, M., Byrne, D. G., \& Haugan, G. (2016). The association between school stress, life satisfaction and depressive symptoms in adolescents: Life satisfaction as a potential mediator. Social Indicators Research, 125(1), 339-357. https://doi.org/10.1007/s11205-014-0842-0.

Nock, M. K., Joiner, T. E., Gordon, K. H., Lloyd-Richardson, E., \& Prinstein, M. J. (2006). Non-suicidal self-injury among adolescents: Diagnostic correlates and relation to suicide attempts. Psychiatry Research, 144(1), 65-72. https://doi.org/10.1016/j.psychres.2006.05.010.

Oishi, S., Diener, E., \& Lucas, R. E. (2009). The optimum level of well-being: Can people be too happy? In E. Diener (Ed.), The science of well-being: The collected works of Ed Diener (pp. 175-200). Dordrecht, Netherlands: Springer

Park, N. (2004). The role of subjective well-being in positive youth development. The Annals of the American Academy of Political and Social Science, 591(1), 25-39. https://doi.org/10.1177/00027 16203260078 .

Peterson, J., Freedenthal, S., Sheldon, C., \& Andersen, R. (2008). Nonsuicidal self injury in adolescents. Psychiatry, 5(11), 20-26.

Proctor, C. L., Linley, P. A., \& Maltby, J. (2009). Youth life satisfaction: A review of the literature. Journal of Happiness Studies, 10(5), 583-630. https://doi.org/10.1007/s10902-008-9110-9.

Raaijmakers, Q. A., Engels, R. C., \& Van Hoof, A. (2005). Delinquency and moral reasoning in adolescence and young adulthood. International Journal of Behavioral Development, 29(3), 247-258. https://doi.org/10.1080/01650250544000035.

Rönkä, A. R., Taanila, A., Koiranen, M., Sunnari, V., \& Rautio, A. (2013). Associations of deliberate self-harm with loneliness, self-rated health and life satisfaction in adolescence: Northern Finland Birth Cohort 1986 Study. International Journal of Circumpolar Health, 72(1), 21085. https://doi. org/10.3402/ijch.v72i0.21085.

Schei, J., Jozefiak, T., Nøvik, T. S., Lydersen, S., \& Indredavik, M. S. (2016). The impact of coexisting emotional and conduct problems on family functioning and quality of life among adolescents with ADHD. Journal of Attention Disorders, 20(5), 424-433. https://doi.org/10.1177/108705471350797 6.

Schermelleh-Engel, K., Moosbrugger, H., \& Müller, H. (2003). Evaluating the fit of structural equation models: Tests of significance and descriptive goodness-of-fit measures. Methods of Psychological Rsearch Online, 8(2), 23-74.

Semmer, N. K., Tschan, F., Elfering, A., Kälin, W., \& Grebner, S. (2005). Young adults entering the workforce in Switzerland: Working conditions and well-being. In H. Kriesi, P. Farago, M. Kohli, \& M. Zarin-Nejadan (Eds.), Contemporary Switzerland: Revisiting the special case (pp. 163-189). Houndmills, United Kingdom: Palgrave Macmillan.

Shek, D. T. L. (1998). Adolescent positive mental health and psychological symptoms: A longitudinal study in a Chinese context. Psychologia: An International Journal of Psychology in the Orient, 41(4), 217-225.

Shek, D. T. L., \& Liang, L.-Y. (2018). Psychosocial factors influencing individual well-being in Chinese adolescents in Hong Kong: A six-year longitudinal study. Applied Research in Quality of Life, 13(3), 561-584. https://doi.org/10.1007/s11482-017-9545-4.

Shek, D. T. L., \& Lin, L. (2017). Use of foul language among Chinese adolescents: Developmental change and relations with psychosocial competences. Journal of Adolescent Health, 60(3), 313319. https://doi.org/10.1016/j.jadohealth.2016.10.010.

Shek, D. T. L., \& Wu, F. K. Y. (2016). The Project P.A.T.H.S. in Hong Kong: Work done and lessons learned in a decade. Journal of Pediatric and Adolescent Gynecology, 29(1), S3-S11. https://doi. org/10.1016/j.jpag.2015.10.003. 
Shek, D. T. L., Yu, L., Wu, F. K. Y., Zhu, X., \& Chan, K. H. Y. (2017). A 4-year longitudinal study of well-being of Chinese university students in Hong Kong. Applied Research in Quality of Life, 12(4), 867-884. https://doi.org/10.1007/s11482-016-9493-4.

Shek, D. T. L., \& Zhu, X. (2018). Self-reported risk and delinquent behavior and problem behavioral intention in Hong Kong adolescents: The role of moral competence and spirituality. Frontiers in Psychology, 9, 430. https://doi.org/10.3389/fpsyg.2018.00430.

Shek, D. T. L., \& Zhu, X. (2019). Reciprocal relationships between moral competence and externalizing behavior in junior secondary students: A longitudinal study in Hong Kong. Frontiers in Psychology, 10, 528. https://doi.org/10.3389/fpsyg.2019.00528.

Sheldon, K. M., \& Lucas, R. E. (2014). Stability of happiness: Theories and evidence on whether happiness can change. New York, NY: Springer.

Silbereisen, R. K., \& Lerner, R. M. (2007). Approaches to positive youth development: A view of the issues. In R. K. Silbereisen \& R. M. Lerner (Eds.), Approaches to positive youth development (pp. 3-30). Thousand Oaks, CA: Sage Publications.

Steinberg, L., \& Lerner, R. M. (2004). The scientific study of adolescence: A brief history. The Journal of Early Adolescence, 24(1), 45-54. https://doi.org/10.1177/0272431603260879.

Steinmayr, R., Crede, J., McElvany, N., \& Wirthwein, L. (2016). Subjective well-being, test anxiety, academic achievement: Testing for reciprocal effects. Frontiers in Psychology, 6, Aricle 1994, https ://doi.org/10.3389/fpsyg.2015.01994.

Suldo, S. M., \& Huebner, E. S. (2004). Does life satisfaction moderate the effects of stressful life events on psychopathological behavior during adolescence? School Psychology Quarterly, 19(2), 93-105. https ://doi.org/10.1521/scpq.19.2.93.33313.

Suldo, S. M., \& Huebner, E. S. (2006). Is extremely high life satisfaction during adolescence advantageous? Social Indicators Research, 78(2), 179-203. https://doi.org/10.1007/s11205-005-8208-2.

Sun, R. C. F., \& Shek, D. T. L. (2012). Positive youth development, life satisfaction and problem behaviour among Chinese adolescents in Hong Kong: A replication. Social Indicators Research, 105(3), 541-559. https://doi.org/10.1007/s11205-011-9786-9.

Tolan, P., Ross, K., Arkin, N., Godine, N., \& Clark, E. (2016). Toward an integrated approach to positive development: Implications for intervention. Applied Developmental Science, 20(3), 214-236. https:// doi.org/10.1080/10888691.2016.1146080.

Valois, R. F., Paxton, R. J., Zullig, K. J., \& Huebner, E. S. (2006). Life satisfaction and violent behaviors among middle school students. Journal of Child and Family Studies, 15(6), 695-707. https://doi. org/10.1007/s10826-006-9043-Z.

Valois, R. F., Zullig, K. J., Huebner, E. S., \& Drane, J. W. (2001). Relationship between life satisfaction and violent behaviors among adolescents. American Journal of Health Behavior, 25(4), 353-366. https:// doi.org/10.5993/AJHB.25.4.1.

Valois, R. F., Zullig, K. J., Huebner, E. S., \& Drane, J. W. (2004). Life satisfaction and suicide among high school adolescents. Social Indicators Research, 66(1), 81-105. https://doi.org/10.1023/B:SOCI.00000 07499.19430.2f.

van Den Eijnden, R. J. J. M., Koning, I., Doornwaard, S., Van Gurp, F., \& Ter Bogt, T. (2018). The impact of heavy and disordered use of games and social media on adolescents' psychological, social, and school functioning. Journal of behavioral addictions, 7(3), 697-706. https://doi.org/10.1556/2006.7.2018.65.

Van Meter, A. R., Algorta, G. P., Youngstrom, E. A., Lechtman, Y., Youngstrom, J. K., Feeny, N. C., et al. (2018). Assessing for suicidal behavior in youth using the Achenbach System of Empirically Based Assessment. European Child \& Adolescent Psychiatry, 27(2), 159-169. https://doi.org/10.1007/s0078 7-017-1030-y.

Whillans, A. V., Chen, F., \& Jordan, A. (2020). The upside to feeling worse than average. Frontiers in Psychology, 11, 642. https://doi.org/10.3389/fpsyg.2020.00642.

Yang, D., \& Zhou, H. (2017). The comparison between Chinese and Western well-being. Open Journal of Social Sciences, 5(11), 181-188. https://doi.org/10.4236/jss.2017.511013.

Yu, L., \& Shek, D. T. L. (2018). Testing longitudinal relationships between Internet addiction and wellbeing in Hong Kong adolescents: Cross-lagged analyses based on three waves of data. Child Indicators Research, 11(5), 1545-1562. https://doi.org/10.1007/s12187-017-9494-3.

Yuen, K. S. L., \& Lee, T. M. C. (2003). Could mood state affect risk-taking decisions? Journal of Affective Disorders, 75(1), 11-18. https://doi.org/10.1016/S0165-0327(02)00022-8.

Zapolski, T. C. B., Cyders, M. A., \& Smith, G. T. (2009). Positive urgency predicts illegal drug use and risky sexual behavior. Psychology of Addictive Behaviors, 23(2), 348-354. https://doi.org/10.1037/ a0014684.

Zeman, J., Cassano, M., Perry-Parrish, C., \& Stegall, S. (2006). Emotion regulation in children and adolescents. Journal of Developmental and Behavioral Pediatrics, 27(2), 155-168. 
Zhang, G., \& Veenhoven, R. (2008). Ancient Chinese philosophical advice: can it help us find happiness today? Journal of Happiness Studies, 9(3), 425-443. https://doi.org/10.1007/s10902-006-9037-y.

Zhu, X., \& Shek, D. T. L. (2020). The influence of adolescent problem behaviors on life satisfaction: Parent-child subsystem qualities as mediators. Child Indicators Research, 13, 1767-1789. https://doi. org/10.1007/s12187-020-09719-7.

Publisher's Note Springer Nature remains neutral with regard to jurisdictional claims in published maps and institutional affiliations. 